\title{
Antiferromagnetic Interlayer Coupling of Ni/Mo Superlatices*
}

\author{
Eric E. Fullerton, J.E. Matson, C.H. Sowers, S.D. Bader \\ Materials Science Division \\ Argonne National Laboratory, Argonne, IL 60439
}

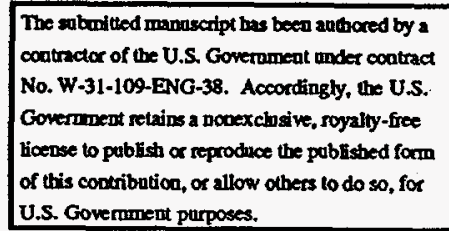

jimc

\footnotetext{
*Work supported by the U.S. Department of Energy , Basic Energy Sciences-Materials Sciences, under contract \#W-31-109-ENG-38.
}

\section{DISCLAIMER}

This report was prepared as an account of work sponsored by an agency of the United States Government. Neither the United States Government nor any agency thereof, nor any of their employees, makes any warranty, express or implied, or assumes any legal liability or responsibility for the accuracy, completeness, or usefulness of any information, apparatus, product, or process disclosed, or represents that its use would not infringe privately owned rights. Reference herein to any specific commercial product, process, or service by trade name, trademark, manufacturer, or otherwise does not necessarily constitute or imply its endorsement, recommendation, or favoring by the United States Government or any agency thereof. The views and opinions of authors expressed herein do not necessarily state or reflect those of the United States Government or any agency thereof. 


\section{DISCLAIMER}

Portions of this document may be illegible in electronic image products. Images are produced from the best available original document. 


\title{
Antiferromagnetic Interlayer Coupling of Ni/Mo Superlattices*
}

\author{
Eric E. Fullerton, J. E. Mattson, C. H. Sowers, and S. D. Bader
}

Materials Science Division

Argonne National Laboratory

Argonne, Il 60439

Structural and magnetic properties of sputtered Ni/Mo superlattices were studied for $\mathrm{Ni}$ thicknesses of 14 and $30 \AA$ and Mo thicknesses from 3 to $25 \AA$. The sign of the interlayer magnetic coupling oscillates between ferromagnetic and antiferromagnetic (AF) with a period of $\approx 12 \AA$ of Mo thickness. The oscillation is similar in phase to that for Co/Mo superlattices, but is shifted out of phase from that published for $\mathrm{Fe} / \mathrm{Mo}$ superlattices, in accord with theoretical expectation. The temperature dependence of the saturation magnetization below $\sim 150 \mathrm{~K}$ follows a $\mathrm{T}^{3 / 2}$-behavior for the $30-\AA$ Ni films and is quasi-linear, TlnT, for the $14-\AA$ films, which indicates a dimensionality crossover from 3D to 2D, respectively.

PACS\# 75.70.-i, 75.70.Fr, 68.65.+g

* Work supported by the U.S. Department of Energy, BES-Materials Sciences, under contract W-31-109-ENG-38. 
$\mathrm{Ni} / \mathrm{Mo}$ was among the first examples of metallic heterostructures that were found to grow as high-quality superlattices. ${ }^{1}$ As a result, there is a significant body of work in the literature that examines its structural, ${ }^{1-3}$ elastic, ${ }^{1,4}$ transport ${ }^{1,5}$ and magnetic properties. ${ }^{6,7}$ Most recently considerable interest has focused on the indirect exchange coupling of magnetic layers interleaved with nonmagnetic metals in superlattice structures. $8-11$ Oscillations in the sign of the interlayer coupling have been observed for a wide variety of nonmagnetic spacer materials. ${ }^{8}$ However, no prior study, to our knowledge, has been devoted to the interlayer magnetic coupling of the $\mathrm{Ni} / \mathrm{Mo}$ system. In this Letter, we report structural and magnetic properties of sputtered Ni/Mo superlattices and compare the results to similar studies of $\mathrm{Fe} / \mathrm{Mo}^{10}$ and $\mathrm{Co} / \mathrm{Mo}^{8,12}$ superlattices. We find that $\mathrm{Ni} / \mathrm{Mo}$ superlattices possess an interlayer coupling which oscillates with a phase and period close to that found for $\mathrm{Co} / \mathrm{Mo}$, but out of phase with that reported for Fe/Mo superlattices, in agreement with recent predictions ${ }^{13,14} \mathrm{We}$ also, find that at low temperature the magnetization (and the interfacial coupling energy) follow a two-dimensional TlnT law for superlattices with thin $\mathrm{Ni}$ layers, as recented predicted. ${ }^{15}$ Our work is based on series of $\mathrm{Ni} / \mathrm{Mo}$ superlattices grown by d.c. magnetron sputtering, as described in Ref. 10. The Mo-layer thicknesses range from 3-25 and the Ni-layer thicknesses are 14 and $30 \AA$. We characterized the structure with $\mathrm{x}$-ray diffraction (XRD) and the magnetic properties by SQUID magnetometry.

Both low-angle and crystalline high-angle XRD superlattice peaks were observed for all Mo thicknesses, indicative of good chemical layering and structural coherence. XRD spectra for a $[\mathrm{Ni}(14 \AA) / \mathrm{Mo}(19 \AA)]_{20}$ superlattice are shown in Fig. 1. To determine the out-of-plane crystal structure, the high-angle spectrum was refined to a general structural model.3,16,17 The result is shown by the solid line in Fig. 1a. The spectrum could not successfully be refined by assuming that the strain profile of the Mo-on-Ni interface is equivalent to that of the Ni-on-Mo interface. This is consistent with the results of Ref. 3, where asymmetric strains in the Ni layers were found. Shown in the inset of Fig. 1a is the average Mo (squares) and Ni (circles) lattice spacings in the growth direction for the $[\mathrm{Ni}(14 \AA) / \mathrm{Mo}]_{20}$ series. The average $\mathrm{Ni}$ lattice spacing is expanded over the bulk value by $\approx 3 \%$ for all Mo thicknesses. The Mo layer is contracted relative to its bulk value, 
with the magnitude depending strongly on Mo thickness. Figure $1 \mathrm{~b}$ shows four low-angle Bragg reflections, and higher frequency finite-size oscillations indicative of smooth layers with limited cumulative roughness. ${ }^{18}$ The low-angle spectrum was fitted to a general optical formalism ${ }^{19}$ (solid line in Fig. 1b) in which the interfacial profiles were assumed to be of Gaussian width $\sigma$. The fitted value for $\sigma$ of $2.5 \AA$ characterizes the interfacial roughness and/or chemical interdiffusion. The layer-thickness values are consistent with those obtained from the high-angle data to better than $1 \AA$.

Selected samples were removed from their substrates and transmission XRD was performed to determine the in-plane structure. The samples are polycrystaline in-plane. The transmission results for a $\mathrm{Ni}(11 \AA) / \mathrm{Mo}(11 \AA)$ superlattice show that the Mo layers asymmetrically

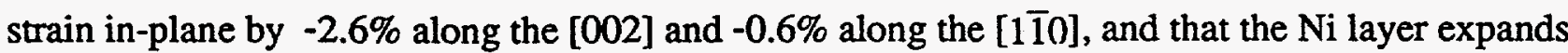
$\approx 1.6 \%$ along the $[2 \overline{2} 0]$ direction. The strain anisotropy is due to the large difference in latticemismatch along orthogonal directions, and is consistent with studies of a number of other fcc/bcc superlattices. ${ }^{2,20,21}$ For thicker layers, the lattice strains relax and bulk spacings are approached.

The results for the thickness dependence of the saturation magnetization $\left(\mathrm{M}_{S}\right)$ and the Curie temperature $\left(\mathrm{T}_{\mathrm{C}}\right)$ are in quantitative agreement with previous studies. ${ }^{6}$ The low-temperature $\left(\mathrm{T}=5 \mathrm{~K}\right.$ ) moment of the $\mathrm{t}_{\mathrm{N}_{\mathrm{i}}}=14 \AA$ and $30 \AA$ films are $125 \pm 20$ and $310 \pm 20 \mathrm{emu} / \mathrm{cc}$, respectively. These values are significantly reduced from the bulk value of $522 \mathrm{emu} / \mathrm{cc}$. SQUID measurements give an average magnetization; without a measurement of the magnetization profile, we cannot differentiate between changes in the average moments $v s$. interfacial moments.

$\mathrm{MS}(\mathrm{T})$ for $[\mathrm{Ni}(30 \AA) / \mathrm{Mo}(12) \AA)]_{20}$ and $[\mathrm{Ni}(14 \AA) / \mathrm{Mo}(12 \AA)]_{20}$ superlattices are shown in Fig. 2. The $t_{\mathrm{Ni}}=14 \AA$ films have low- $\mathrm{T}_{\mathrm{C}}$ values (near $200 \mathrm{~K}$ ) and the $\mathrm{t}_{\mathrm{Ni}}=30-\AA$ films order well above room temperature. We fitted the $t_{N i}=30 \AA M_{S}-v s-T$ data to a standard power-law expression:

$$
\mathrm{M}_{S}(\mathrm{~T})=\mathrm{MS}_{\mathrm{S}}(0)\left[1-\mathrm{a} \mathrm{T}^{\alpha}\right]
$$

as shown by the solid line in Fig. 2a. The $30 \AA \mathrm{Ni}$ films follow the expected 3D T $\mathrm{T}^{3 / 2}$ behavior. The exponent is insensitive to the $T$ range selected for the fit, and varies by only 0.05 when the upper T-range of the fit is increased from 75 to $225 \mathrm{~K}$. The temperature dependence of $\mathrm{MS}_{\mathrm{S}}$ for the 
$\mathfrak{t}_{\mathrm{Ni}}=14 \AA$ sample is qualitatively different, as seen in Fig. $2 \mathrm{~b}$. In this case $\mathrm{MS}_{\mathrm{S}}(\mathrm{T})$ is best fitted by the quasi-linear relation:

$$
\mathrm{M}_{S}(\mathrm{~T})=\mathrm{M}_{S}(0)[1-\mathrm{b} T \ln \mathrm{T}],
$$

which is the expected spin-wave behavior for a 2D magnetic layer. ${ }^{15,22}$

The $\mathrm{Ni}$ interlayer coupling was determined from the saturation field $\left(\mathrm{H}_{\mathrm{S}}\right)$ of the magnetic hysteresis loops. Shown in Fig. 3 are the low field regions measured at $\mathrm{T}=50 \mathrm{~K}$ for the $[\mathrm{Ni}(14 \AA) / \mathrm{Mo}]_{20}$ superlattices with $\mathrm{t}_{\mathrm{Mo}}=7,12$ and $19 \AA$. The $\mathrm{t}_{\mathrm{Mo}}=7$ - and $19-\AA$ samples show the characteristic features of AF coupling, a large $\mathrm{H}_{S}$ value and a magnetization plateau at low fields. The intermediate $\mathrm{Mo}$ thickness $\left(\mathrm{t}_{\mathrm{Mo}}=12 \AA\right)$ sample has a square hysteresis loop indicative of either uncoupled or ferromagnetically coupled Ni layers. $\mathrm{H}_{S} v s$ Mo thickness is plotted in Fig. $3 b$. $H_{S}$ is peaked at $\mathrm{t}_{\mathrm{Mo}}=6$ and $18 \AA$ which yields a periodicity of $\approx 12 \AA$ in agreement with the $11-\AA$ period found for both $\mathrm{Fe} / \mathrm{Mo}^{10}$ and $\mathrm{Co} / \mathrm{Mo}^{8,12}$ superlattices. The phase of the oscillation agrees with that for $\mathrm{Co} / \mathrm{Mo}$, but is out of phase with respect to $\mathrm{Fe} / \mathrm{Mo}$ where the first $\mathrm{AF}$ peak appears at $t_{\mathrm{Mo}}=12 \AA$. This result also agrees with the recent theoretical work, 13,14 which predicts that the AF coupling in Co- and Ni-based superlattices should oscillate with similar phase but different from that in $\mathrm{Fe}$ based superlattices.

The temperature dependence of the AF-coupling energetics was studied for the $14-\AA \AA A \mathrm{Ni}$ superlattice. Figure $4 \mathrm{a}$ contains hysteresis loops for $[\mathrm{Ni}(14 \AA) / \mathrm{Mo}(7 \AA)]_{20}$ that show that the $\mathrm{MS}_{\mathrm{S}}$ values change by a factor of four between 25 and $150 \mathrm{~K}$, due to the low $\mathrm{T}_{\mathrm{C}}$ value. Figure $4 \mathrm{~b}$ shows the same data normalized to Ms. The shape of the hysteresis loops are nearly identical with no measurable change in $H_{s}$ value. Since the interfacial coupling energy is approximately equal to $\mathrm{H}_{S} \mathrm{M}_{S} \mathrm{t}_{\mathrm{Ni}} / 4$, the constancy of $\mathrm{H}_{S}$ implies that the coupling energy possesses the same $\operatorname{Tn} \mathrm{T}$ dependence as $\mathrm{MS}_{\mathrm{S}}$ over this temperature range, in agreement with recent theoretical analysis by Cullen and Hathaway. ${ }^{15}$ In comparing the coupling energies of the $\mathrm{t}_{\mathrm{Ni}}=14$ and $30 \AA$ samples, we find that the product $\mathrm{H}_{\mathrm{S}} \mathrm{t}_{\mathrm{Ni}}$ remains constant. This confirms that the coupling energy scales with $\mathrm{M}_{S}$ even though $\mathrm{M}_{S}$ has increased by $\sim 250 \%$ for the thicker Ni layers. (Similar measurements of the dependence of the coupling energy and $\mathrm{MS}_{S}$ on $\mathrm{T}$ for the second AF-coupling peak were 
hampered by the strong temperature dependence of the coercive field $\mathrm{H}_{\mathrm{c}}$. For low temperatures, the value of $\mathrm{H}_{c}$ becomes comparable to that of $\mathrm{H}_{S}$ and small changes in $\mathrm{H}_{S}$ are difficult to resolve. Nonetheless, the changes in $\mathrm{H}_{\mathrm{S}}$ are significantly smaller than those in $\mathrm{MS}_{\mathrm{S}}$ )

In summary, we presented structural and magnetic properties of sputtered Ni/Mo superlattices. We find the AF coupling oscillates with a period of $\approx 12 \AA$. The phase of the oscillation is similar to that for Co/Mo superlattices, but is out of phase with that observed in Fe/Mo superlattices. The temperature dependence of $\mathrm{MS}$ exhibits a crossover from 2D-to-3D behavior as a function of increasing Ni thickness. Both $\mathrm{MS}_{\mathrm{S}}$ and the AF coupling energy for the 14- $\AA$ Ni possess the predicted TInT behavior at low temperature, while thicker Ni films follow the $\mathrm{T}^{3 / 2}$ Bloch law.

Acknowledgment

Work supported by the U.S. Department of Energy, BES-Materials Sciences, under contract W-31-109-ENG-38. 


\section{References:}

1. M. R. Khan, C. S. L. Chun, G. P. Felcher, M. Grimsditch, A. Kueny, C. M. Falco, and I. K. Schuller, Phys. Rev. B 27, 7186 (1983).

2. J. A. Bain, L. J. Chyung, S. Brennan, and B. M. Clemens, Phys. Rev. B 44, 1184 (1991).

3. I. K. Schuller, E. E. Fullerton, H. Vanderstraeten, Y. Bruynseraede, Strucuture/Property Relationships for Metal/Metal Interfaces, edited by A. D. Romig, D. E. Fowler, and P.D. Bistowe (Mater. Res. Soc. Symp. Proc. 229, Pittsburgh, PA, 1991) p. 41.

4. B. M. Clemens and G. L. Eesley, Phys. Rev. Lett. 61, 2356 (1988).

5. R. Clarke, D. Morelli, C. Uher, H. Homma, and I. K. Schuller, Superlattices and Microstructures 1, 125 (1985).

6. I. K. Schuller and M. Grimsditch, J. Appl. Phys. 55, 2491 (1984).

7. M. J. Pechan and I. K. Schuller, Phys. Rev. Lett. 59, 132 (1987); M. J. Pechan, J. Appl. Phys. 64, 5754 (1988).

8. S. S. P. Parkin, Phys. Rev. Lett. 67, 3598 (1991).

9. C. A. dos Santos, B. Rodmacq, M. Vaezzadey, and B. George, Appl. Phys. Lett. 59, 126 (1991).

10. M. E. Brubaker, J. E. Mattson, C. H. Sowers, and S. D. Bader, Appl. Phys. Lett. 58, 2306 (1991).

11. J. E. Mattson, C. H. Sowers, A. Berger, and S. D. Bader, Phys. Rev. Lett. 68, 3252 (1992).

12. E. E. Fullerton, J. E. Mattson, C.H. Sowers, and S. D. Bader, unpublished.

13. J. Mathon, M. Villere, and D. M. Edwards, J. Phys: Condens. Matter 4, 9873 (1992).

14. P. Bruno, J. Magn. Magn. Mater. 116, L13 (1992).

15. J. R. Cullen and K. Hathaway, Phys. Rev. B (in press).

16. E. E. Fullerton, I. K. Schuller, H. Vanderstraeten, Y. Bruynseraede, Phys. Rev. B 45, 9292 (1992).

17. E. E. Fullerton, I. K. Schuller, Y. Bruynseraede, MRS Bulletin XVII (12), 33 (1992). 
18. A. P. Payne and B. M. Clemens, Phys. Rev. B 47, 2289 (1993).

19. J. H. Underwood and T. W. Barbee, Appl. Opt. 20, 3027 (1981).

20. E. E. Fullerton, S. Kumar, M. Grimsditch, D. M. Kelly, I. K. Schuller, Phys. Rev. B (in press).

21. A. Fartash, M. Grimsditch, E. E. Fullerton, I. K. Schuller, Phys. Rev. B (in press).

22. Z. Q. Qui, J. E. Mattson, C. H. Sowers, U. Welp, S. D. Bader, H. Tang, and J. C. Walker, Phys. Rev. B 45, 2252 (1992). 
Figure 1: (a) High-angle and (b) low-angle $\mathrm{x}$-ray diffraction result for a $[\mathrm{Ni}(14 \AA) / \mathrm{Mo}(19 \AA)]_{20}$ superlattice. Open circles are measured intensities and the solid line represents the best fit. The inset shows average Mo (squares) and $\mathrm{Ni}$ (circles) lattice spacing in the growth direction determined by fitting the high-angle spectra of $\left[\mathrm{Ni}(14 \AA) / \mathrm{Mo}\left(\mathrm{t}_{\mathrm{Mo}}\right)\right]_{20}$ superlattices.

Figure 2: $\quad$ Open squares are the measured $\mathrm{M}_{S}(\mathrm{~T})$ values for (a) $[\mathrm{Ni}(30 \AA \AA) / \mathrm{Mo}(12 \AA)]_{20}$ and (b) $[\mathrm{Ni}(14 \AA) / \mathrm{Mo}(12 \AA)]_{20}$ superlattices. Solid lines are least-squares fits to (a) power law and (b) quasi-linear $\mathrm{T} \ln \mathrm{T}$ behaviors.

Figure 3: (a) Magnetic hysteresis loops for $\left[\mathrm{Ni}(14 \AA \AA) / \mathrm{Mo}\left(\mathrm{t}_{\mathrm{Mo}}\right)\right]_{20}$ superlattices measured at $50 \mathrm{~K}$. (b) $\mathrm{H}_{s}$ vs. $\mathrm{t}_{\mathrm{Mo}}$ for $\left[\mathrm{Ni}(14 \AA) / \mathrm{Mo}\left(\mathrm{t}_{\mathrm{Mo}}\right)\right]_{20}$ superlattices.

Figure 4: Magnetic hysteresis loops for a $[\mathrm{Ni}(14 \AA) / \mathrm{Mo}(7 \AA)]_{20}$ superlattice measured at 25,50 , 100 and $150 \mathrm{~K}$, where (a) shows the absolute magnetization; and (b) shows the normalized magnetization of only half the measured loops for clarity. 

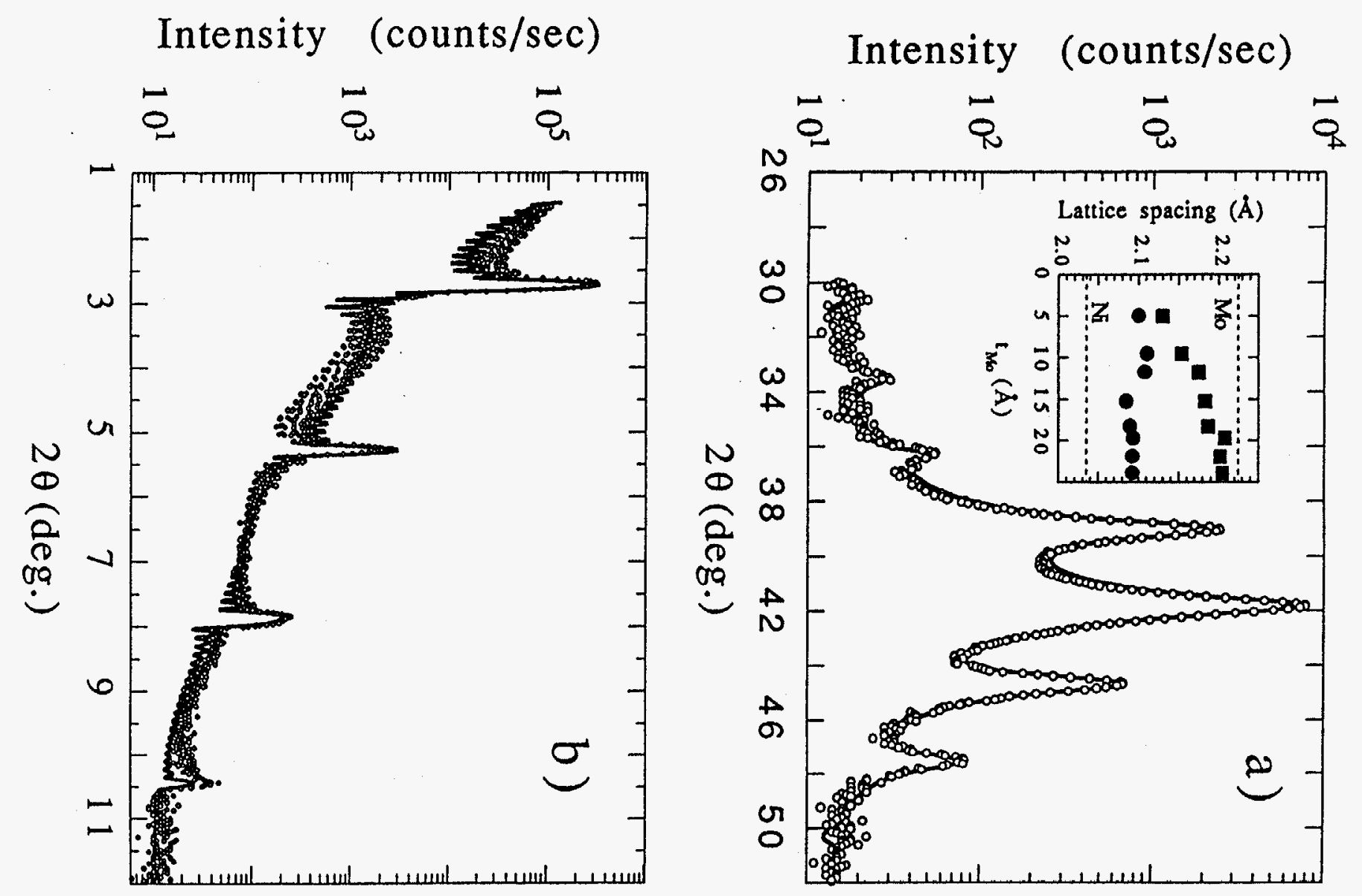

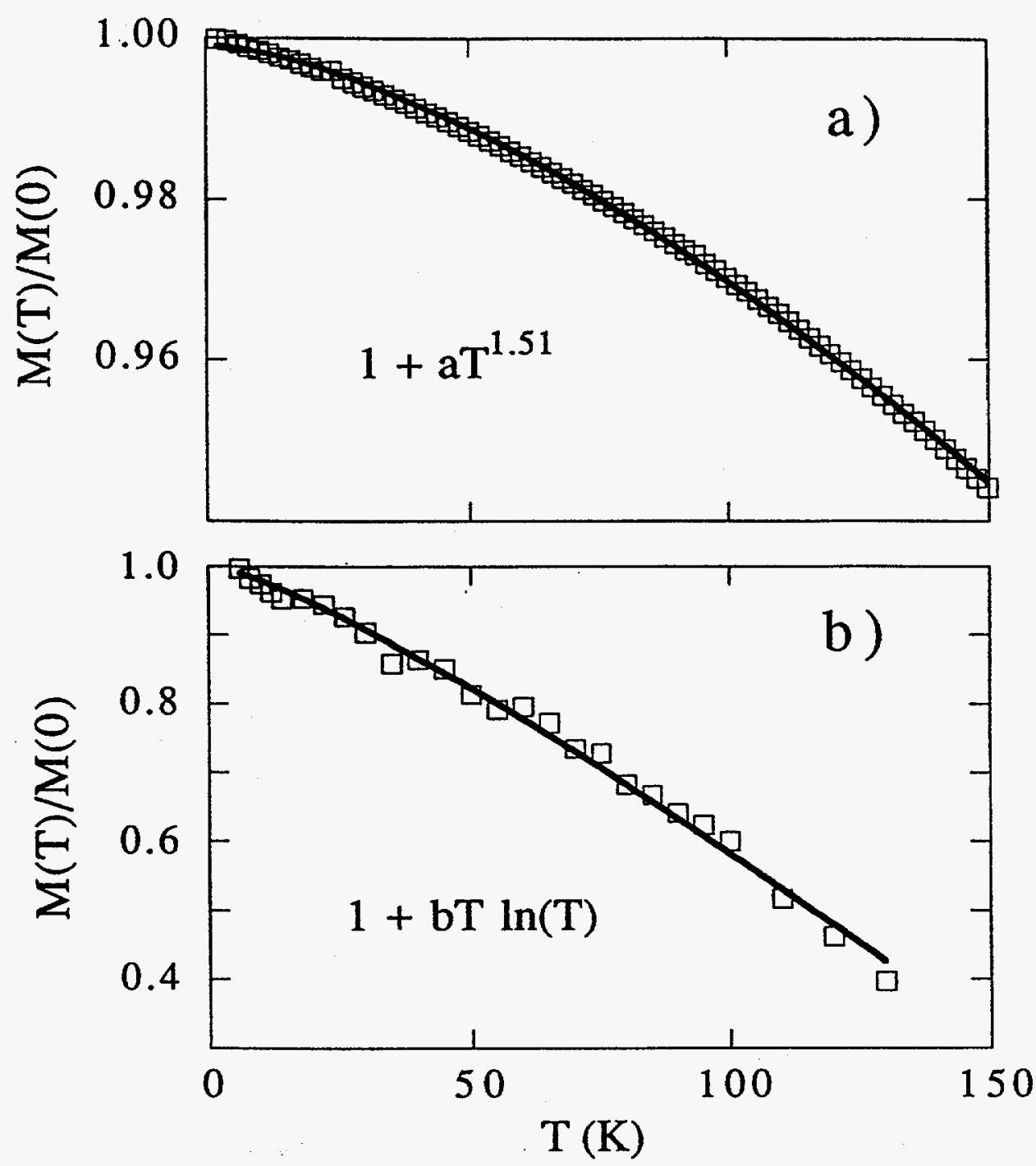

Fullerton et al.

Figure 2 

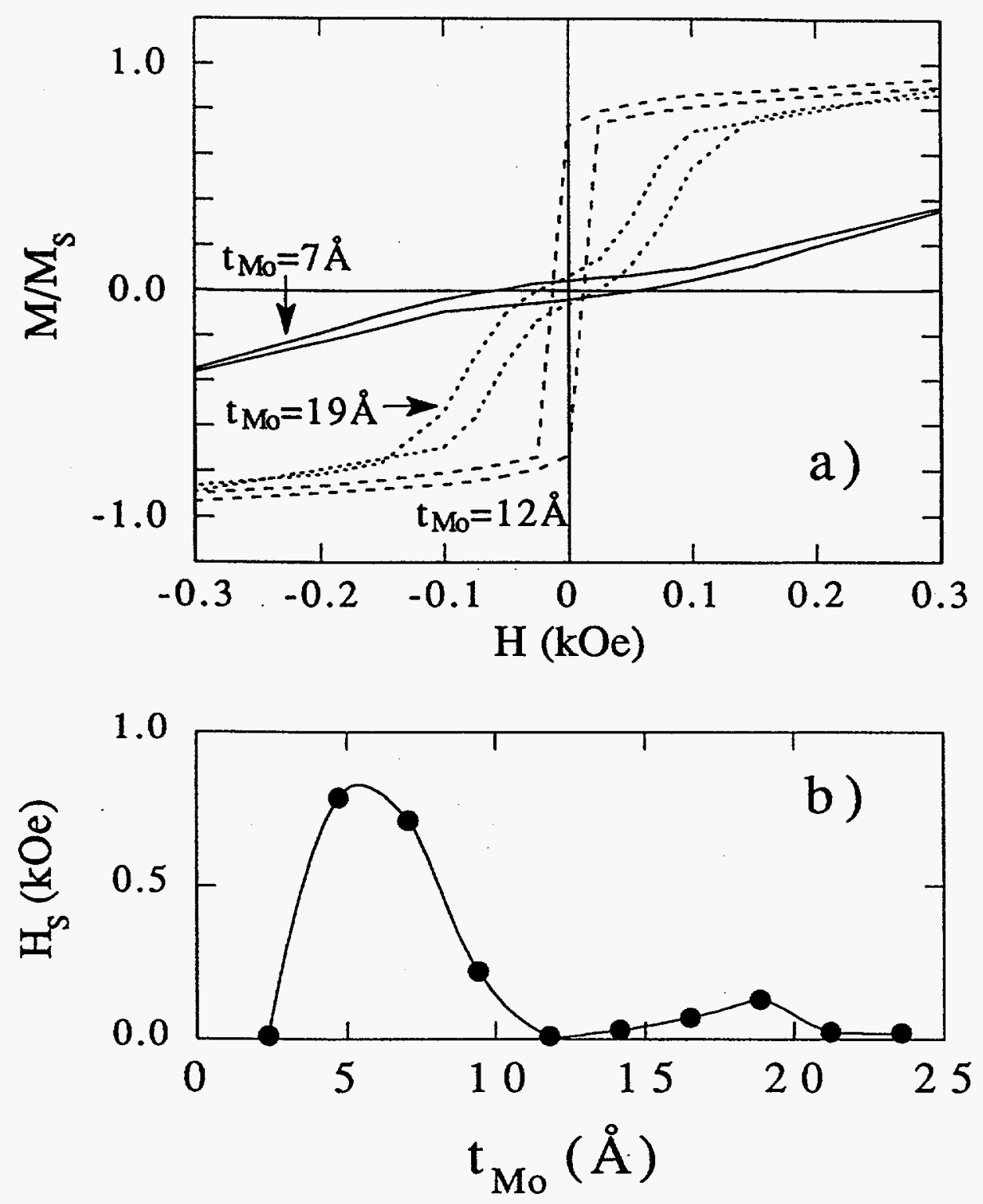

Fullerton et al.

Figure 3 


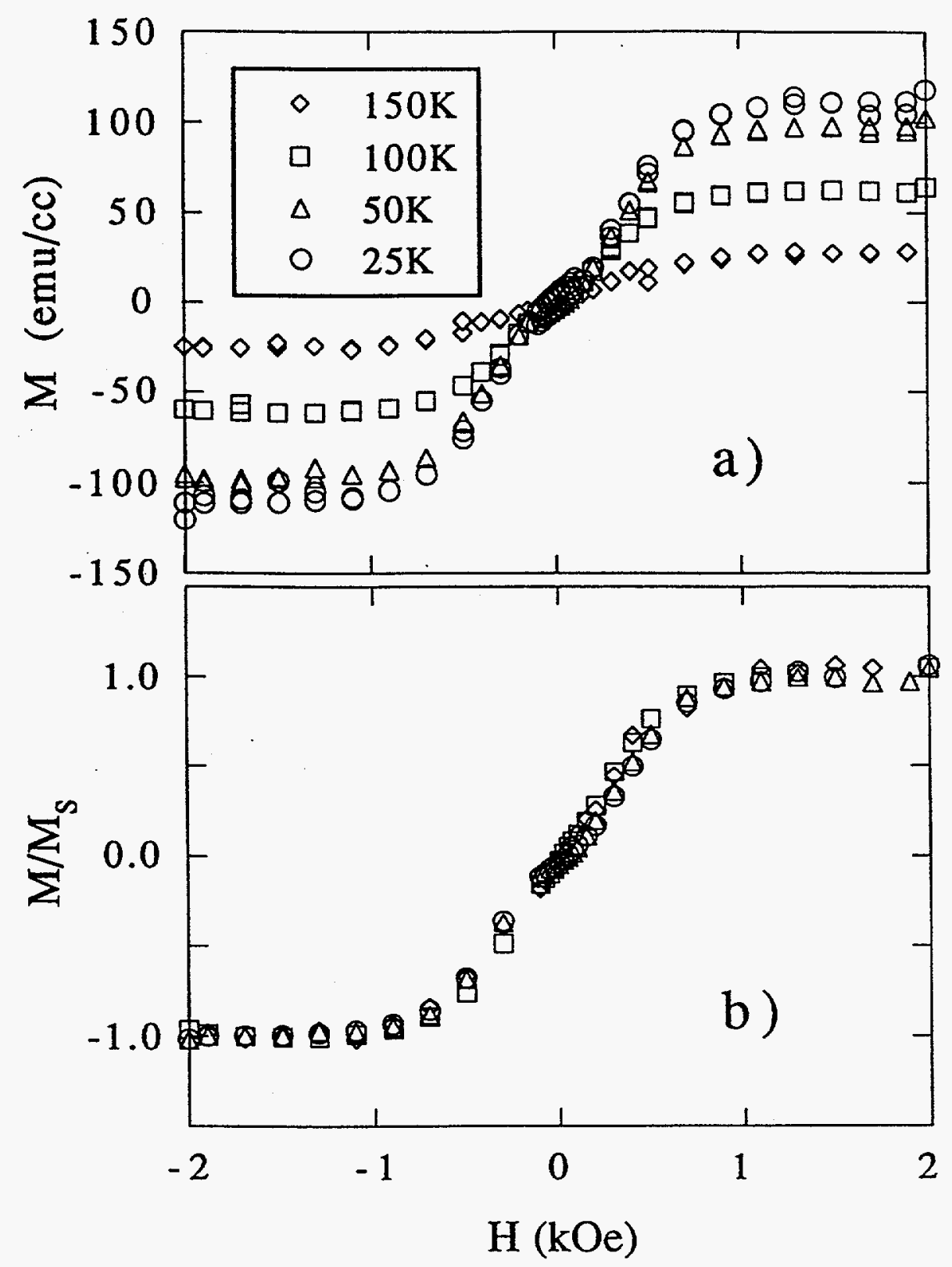

Fullerton et al. Figure 4 